\title{
EMERGÊNCIA DE ACACIA FARNESIANA (L.) Willd. (FABACEAE) E POUTERIA RAMIFLORA Radlk. (SAPOTACEAE) EM DIFERENTES SUBSTRATOS
}

\author{
Fábio Gomes de Oliveira ${ }^{1}$;Mário Augusto Gonçalves Jardim² 3
}

\section{RESUMO}

A propagação vegetativa de espécies arbóreas de restinga pode ser uma alternativa para a restauração ambiental e o paisagismo. O objetivo desta pesquisa foi verificar a influência de diferentes substratos no tempo de emergência das espécies. O experimento foi em blocos casualizados com quatro tratamentos e quatro repetições abrangendo 1.600 sementes para A. farnesiana e 208 sementes de P. ramiflora, sendo, T1- terra preta, T2- areia, T3- terra preta (50\%) + areia (50\%) e T4- vermiculita alocados em bancada suspensa com temperatura ambiente e com tempo de avaliação de 47 dias para A. farnesiana e 114 dias para $P$. ramiflora. A vermiculita proporcionou o maior número de plantas emergidas em menor tempo para as duas espécies por apresentar boa estrutura e elevada capacidade de retenção de água.

Palavras-Chaves: Propagação Sexuada, Restauração Ambiental, Áreas Litorâneas.

\section{EMERGENCY OF THE ACACIA FARNESIANA Willd. (FABACEAE) AND POUTERIA RAMIFLORA Radlk. (SAPOTACEAE) ON THE DIFFERENTS SUBSTRATES}

\section{ABSTRACT}

Vegetative propagation of tree species of sand coastal can be an alternative for environmental restoration and landscaping. The objective of this research was to investigate the influence of different substrates in time of emergency plant Acacia farnesiana (L.) Willd and Pouteria ramiflora Radlk. The experiment was a randomized block with four treatments and four replication covering seeds for 1.600 of A. farnesiana and 208 seeds of the P. ramiflora, being, T1- black soil, T2- sand, T3- black soil (50\%) + sand (50\%) and T4- vermiculite placed in suspended bench at ambiental temperature and whose time assessment was 47 days for A. farnesiana and 114 days for P. ramiflora. The vermiculite provided a greater number of emerged plants in a shorter time for the two species as a result good structure and high water retention capacity.

Keywords: Sexual Propagation, Environmental Restoration, Coastal Areas.

\footnotetext{
${ }^{1}$ Bolsista PIBIC/CNPq. Museu Paraense Emilio Goeldi. Coordenação de Botânica, Belém/Pará: fg_oliveiraufra@yahoo.com.br

${ }^{2}$ Pesquisador Titular. Museu Paraense Emilio Goeldi.Coordenação de Botânica.Belém/Pará: jardim@museu-goeldi.br

${ }^{3}$ recebido em 02.05.2013 e aceito para publicação em 05.12.2013
} 
O processo de germinação corresponde a uma etapa na vida da semente que é influenciado por fatores ambientais e genéticos durante o seu desenvolvimento (Lopes e Pereira 2005). No caso de alterações neste processo, a emergência da planta sofrerá consequências, pois, é um fenômeno primordial para o seu estabelecimento, e caso apresente atraso, poderá ocasionar o menor crescimento da parte aérea e do sistema radicular (Merotto Junior et al. 1999).

O comportamento das espécies quanto ao substrato não é uniforme, uma vez que algumas são mais exigentes e com melhor desempenho germinativo para apenas um tipo de substrato. A escolha do substrato ocorre em função da facilidade e da eficiência do uso e do tipo de semente, pois, é onde o sistema radicular contribuirá no crescimento da parte aérea até o transplantio (Braga Junior et al. 2010; Jabur e Martins 2002). Para Souza et al. (2001) é o responsável pelo fornecimento de nutrientes, disponibilidade e capacidade de retenção de água.

Nos últimos anos, algumas áreas do litoral paraense vêm sofrendo alterações ambientais ocasionadas por investimentos imobiliários, por lazer desordenado e pelo desrespeito e a falta de informação sobre as formas de vidas biológicas ali existentes. Nas restingas da Área de Proteção Ambiental, Algodoal-Maiandeua pretende-se minimizar tais efeitos antrópicos por meio do cultivo e plantio de espécies arbóreas. Pois, esta restinga segundo Ferreira et al. (2013), apresenta espécies com características exuberantes e, apropriadas ao paisagismo.

Dentre as inúmeras espécies que compõem a flora arbórea da restinga foram escolhidas: Acacia farnesiana, árvore de pequeno porte com folhas alternas bipinadas, ramos que crescem em zig-zag e flores de coloração amarelo, esta espécie apresenta alto valor econômico devido suas propriedades madeireiras, forrageira, odorífera e ornamental (Lorenzi 2002). Pouteria ramiflora, árvore lactescente com folhas simples e alternas, flores amareladas e pouco vistosas e é uma frutífera da Amazônia utilizada para fins madeireiros, extração de látex e na dieta alimentar por meio dos frutos (Silva et al. 2001; Gama et al. 2013).

O objetivo deste estudo foi avaliar a influência de diferentes substratos no tempo de emergência de plantas de Acacia farnesiana (L.) Willd. e Pouteria ramiflora Radlk.

\section{MATERIAL E MÉTODOS}

A coleta de frutos foi realizada nos meses de agosto e novembro de 2011 em duas matrizes de uma floresta de restinga alta na Área de Proteção Ambiental, Algodoal-Maiandeua, Maracanã, Pará. Conforme autorização concedida para coleta de material botânico pela Secretaria de Estado e Meio Ambiente (SEMA/nº 017/2010). No campo foram depositados em sacos plásticos de 30kg e transportados para o laboratório de Ecologia vegetal da Coordenação de Botânica do Museu Paraense Emílio Goeldi.

Os frutos de $A$. farnesiana foram abertos com auxílio de tesoura de poda para a retirada das sementes e os de $P$. ramiflora lavados em água 
corrente e depositados por aproximadamente 48 horas em bandejas plásticas contendo água para facilitar a retirada da polpa e, por conseguinte liberar a semente. $\mathrm{O}$ delineamento experimental foi em blocos casualizados com os seguintes tratamentos: T1- terra preta; T2- areia; T3- terra preta $(50 \%)$ + areia (50\%) e T4- vermiculita implantados em caixas plásticas tipo gerbox com tamanho $11 \times 11 \times 3 \mathrm{~cm}$, onde cada tratamento foi composto de quatro repetições com 100 sementes/repetição perfazendo um total de 1.600 sementes para A. farnesiana e com 52 sementes/repetição somando 208 sementes para $P$. ramiflora. O experimento foi conduzido em bancada suspensa em temperatura ambiente na Coordenação de Botânica, do Museu Paraense Emílio Goeldi e avaliados diariamente durante 47 dias para A. farnesiana e 114 dias para $P$. ramiflora quanto à emergência de plantas. Foi utilizado o programa Bioestat 5.0 para as análises estatísticas.

\section{RESULTADOS E DISCUSSÃO}

Foi constatada a emergência de 646 plantas de $A$. farnesiana representando 40,4\%. O T3 foi responsável pelo padrão inicial de emergência no segundo dia (2 plantas), enquanto o T4 iniciou no quarto dia (8 plantas), cuja emergência foi progressiva até aos quarenta e sete dias quando atingiu 252 plantas (63\%; $n=400)$ (Figura 1). Nos demais tratamentos, a emergência iniciou no terceiro dia, e о Т3 promoveu o segundo melhor percentual de emergência (39,8\%; 159 plantas), seguido por T2 (30,5\%; 122 plantas) e T1 (28,2\%; 113 plantas).

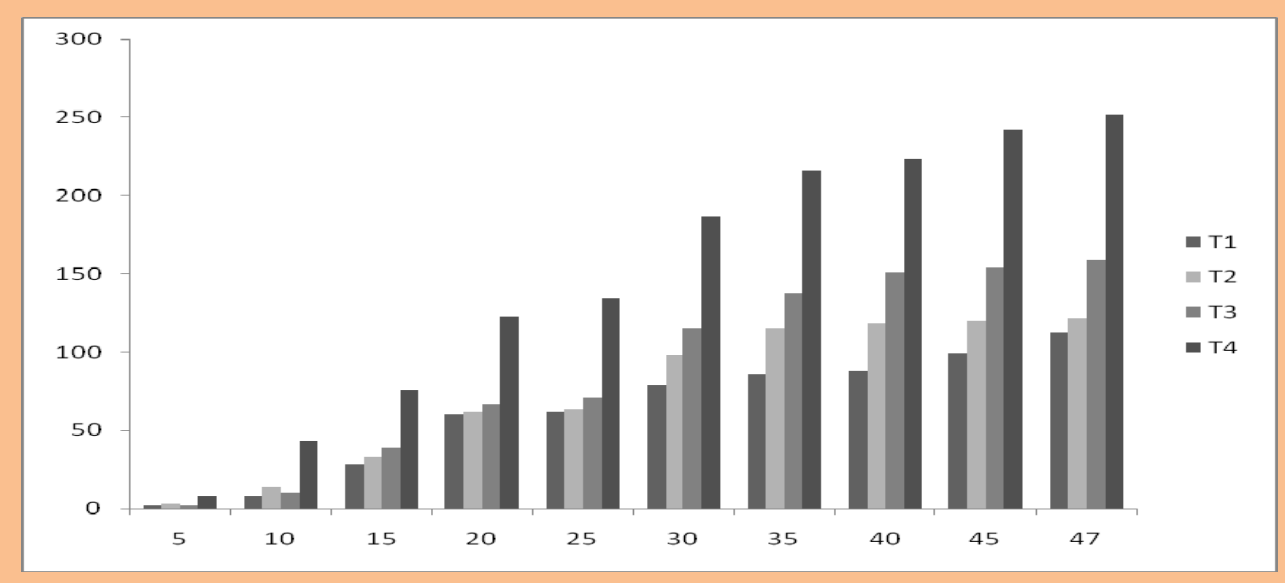

Figura 1. Emergência de plantas de Acacia farnesiana (L.) Willd. durante 47 dias em diferentes substratos. T1- terra preta; T2- areia; T3- terra preta (50\%) + areia (50\%) e T4- vermiculita. N= 1600 .

Na tabela 1 verifica-se que a maior média foi para o T4, que proporcionou a maior emergência de plantas.
Para $P$. ramiflora, observou-se a emergência de 118 plantas perfazendo um total de 56,7\%. No T4 a emergência ocorreu no vigésimo oitavo dia após a 
semeadura (1 planta), tendo efeito progressivo até aos cento e quatorze dias ao qual atingiu 39 plantas (75\%; $n=52)$ (Figura 2). Nos outros tratamentos, o processo de emergência teve inicio no trigésimo quinto dia, e o T1 apresentou o segundo melhor percentual de emergência (57,7\%; 30 plantas), seguido por T2 (55,8\%; 29 plantas) e T3 (38,5\%; 20 plantas).

Tabela 1. Análise estatística do processo de emergência de plântulas de Acacia farnesia em diferentes substratos.

\begin{tabular}{ccccc}
\hline Tratamentos & T1 & T2 & T3 & T4 \\
\hline Média & 28,2 & 30,5 & 39,7 & 63,0 \\
Variância & 20,2 & 27,7 & 9,6 & 12,7 \\
Desvio padrão & 4,5 & 5,3 & 3,1 & 3,6 \\
Erro padrão & 2,2 & 2,6 & 1,5 & 1,8
\end{tabular}

T1- terra preta; T2- areia; T3- terra preta (50\%) + areia (50\%) e T4- vermiculita.

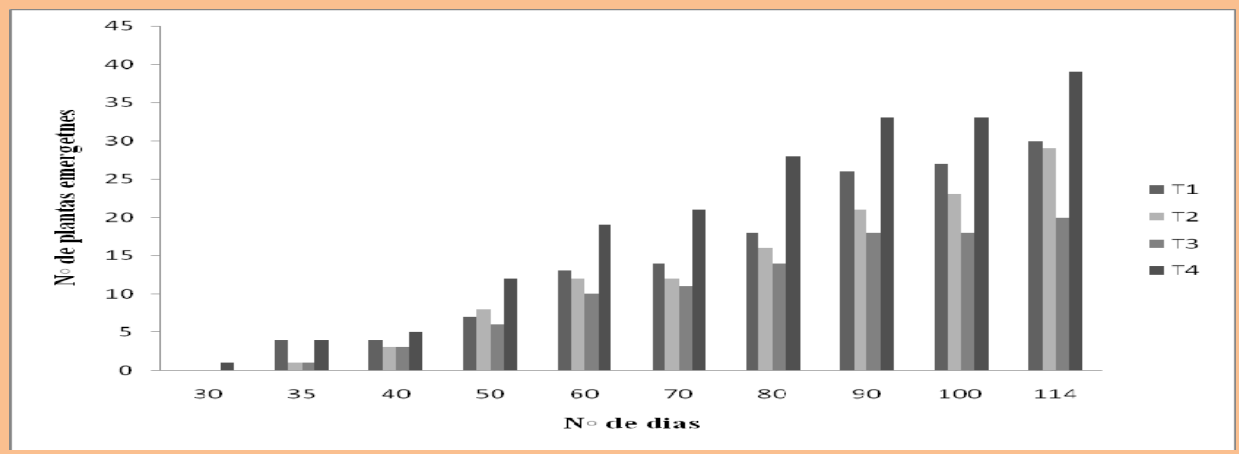

Figura 2. Emergência de plantas de Pouteria ramiflora Radlk. durante 114 dias em diferentes substratos. T1-terra preta; T2- areia; T3- terra preta (50\%) + areia (50\%) e T4- vermiculita. N=208.

A tabela 2 mostra que a maior média foi para o T4, proporcionando o maior número de plantas emergidas.

TABELA 2. Análise estatística do processo de emergência de plântulas de Pouteria ramiflora Radlk. em diferentes substratos.

\begin{tabular}{ccccc}
\hline Tratamentos & T1 & T2 & T3 & T4 \\
\hline Média & 7,5 & 7,2 & 5,0 & 9,7 \\
Variância & 1,8 & 14,2 & 0,7 & 6,9 \\
Desvio padrão & 1,3 & 3,8 & 0,8 & 2,6 \\
Erro padrão & 0,65 & 1,9 & 0,4 & 1,3 \\
\hline
\end{tabular}

T1- terra preta; T2- areia; T3- terra preta (50\%) + areia (50\%) e T4- vermiculita.

Para A. farnesiana, a vermiculita proporcionou o maior número de plantas. Este resultado está de acordo com os Alvino e Raiol (2007) e Andrade et al. (1999) que também mostraram a maior germinação de Ochrama pyramidale e maior porcentagem de plantas emergidas para Euterpe edulis. Provavelmente, esse efeito foi em decorrência ao maior espaço vazio, da menor 
densidade e do maior arejamento existente entre as partículas e, portanto, favorecendo a emergência de plantas (Andrade et al. 2000).

A vermiculita também proporcionou o maior número de plantas emergidas para $P$. ramiflora, corroborando com Santana et al. (2008) quando avaliaram o despolpamento e a emergência de plantas de duas espécies do gênero Pouteria. Resultados similares também foram obtidos por Netto (1998) e Andrade et al. (1994), na germinação e emergência de plantas de Ochrama pyramidale e Cedrela odorata Ruiz e Pav. Estes autores atribuíram tais efeitos a excelente capacidade de retenção de água pela vermiculita.

Por outro lado, a mistura de substratos com terra preta e areia favoreceu apenas a emergência de $A$. farnesiana. Este efeito pode estar relacionado com a peculiaridade da espécie para com o substrato.

A espécie $P$. ramiflora segundo Santana et al. (2008) possui dormência tegumentar, gerando dormência relativa. Esta característica, associada ao substrato inadequado pode influenciar no insucesso do processo de emergência. Este efeito foi mostrado pelo baixo número de plantas emergidas na mistura de terra preta com areia. Para Smiderle e Minami (2001), na produção de mudas de espécies frutíferas, o substrato deve proporcionar retenção de água suficiente para permitir a germinação e, quando saturado, manter quantidades adequadas de espaços porosos para facilitar o fornecimento de oxigênio, indispensável no processo de germinação e desenvolvimento da muda.

Para Cavalcanti e Resende (2006) a utilização de diferentes substratos tem sido uma das maneiras para determinar a melhor forma de propagação, multiplicação, emergência e desenvolvimento de plantas de várias espécies. Por este motivo, é importante considerar determinadas características da planta para a escolha do melhor material na produção de mudas, como por exemplo, a exigência das espécies quanto ao substrato, a emergência e ao desenvolvimento posterior das mudas que podem ser diferentes (Guimarães et al. 2011).

Os substratos testados neste trabalho apresentaram resultados positivos e negativos na emergência de plantas de A. farnesiana e P. ramiflora. É provável que a capacidade de retenção de água de cada substrato aliado as características intrínsecas que regulam o fluxo de água para as sementes possam ter influenciado na emergência das plantas. Para Martins et al. (1999), as plantas que emergem mais rápido podem tornar-se menos vulneráveis as condições adversas do meio por passarem menos tempo nos estádios iniciais de desenvolvimento.

\section{CONCLUSÕES}

A vermiculita proporcionou o maior número de plantas emergidas em menor tempo, por apresentar boa estrutura e elevada capacidade de retenção de água.

\section{AGRADECIMENTOS}

Ao Conselho Nacional de Desenvolvimento

Científico e Tecnológico pelo apoio financeiro no projeto Pesquisa científica e capacitação local como indicadores sustentáveis para restauração ambiental 


\section{REFERÊNCIAS BIBLIOGRÁFICAS}

ALVINO, F. O.; RAIOL, B. P. Efeito de diferentes substratos na germinação de Ochrama pyramidale (Cav. ex. Lam.) Urb. (Bombacaceae). Ciência Florestal. v. 17, n. 1, p. 71-75, 2007.

ANDRADE, A. C.; SOUZA, A. F.; RAMOS, F. N.; PEREIRA, T. S. Efeito do substrato e da temperatura na germinação e no vigor de Cedro (Cedrela odorata L.) (Meliaceae). Revista Brasileira de Sementes. v. 16, n. 1, p. 34-40, 1994.

ANDRADE, C. S. A.; LOUREIRO, M. B.; SOUZA, A. D. O.; RAMOS, F. N.; CRYZ, A. P. M. Reavaliação do efeito do substrato e da temperatura na germinação de sementes de palmiteiro (Euterpe edulis Mart.). Revista Árvore. v. 23, n. 3, p. 279-283, 1999.

ANDRADE, A. C. S.; SOUZA, A. F.; RAMOS, F. N.; PEREIRA, T. S.; CRUZ, A. P. M. Germinação de sementes de jenipapo: temperatura, substrato e morfologia do desenvolvimento pós-seminal. Pesquisa Agropecuária Brasileira. v. 35, n. 2, p. 609-615, 2000.

BRAGA JUNIOR, J. M.; BRUNO, R. L. A.; ALVES, E. U. Emergência de plântulas de Zizyphus joazeiro Mart. (Rhamnaceae) em função de substratos. Revista Árvore. v. 34, n. 4, p. 609-616, 2010.

CAVALCANTI, N. B.; RESENDE, G. M. Efeito de diferentes substratos no desenvolvimento do mandacaru sem espinhos (Cereus hildemannianus K. Schum). Revista Caatinga. v. 19, n. 3, p. 255-260, 2006.

FERREIRA, N. M. M.; SANTOS, J. U. M.; FERREIRA, A. M.; GURGEL, E. S. C. Germinação de sementes e morfologia de plântulas de Myrcia cúprea (O. Berg.) Kiaersk. (Myrtaceae) espécie da restinga com potencial de uso no paisagismo. Revista Brasileira de Arborização Urbana. v. 8, n. 1, p. 27-38, 2013.

GUIMARÃES, I. P.; COELHO, M. F. B.; BENEDITO, C. P.; MAIA, S. S. S.; NOGUEIRA, C. R. S.; BATISTA, P. F. Efeito de diferentes substratos na emergência e vigor de plântulas de mulugú. Biosci. J. v. 27, n. 6, p. 932938, 2011.

JABUR, M. A.; MARTINS, A. B. G. Influência de substratos na formação dos porta-enxertos: limoeiro-cravo (Citrus limonia Osbeck) e tangerina-cleópatra (Citrus reshni Hort. ex Tanaka) em ambiente protegido. Revista Brasileira de Fruticultura. v. 2, n. 2, p. 01-10, 2002.

LOPES, J. C.; PEREIRA, M. D. Germinação de sementes de cubiu em diferentes substratos e temperaturas. Revista Brasileira de Sementes. v. 27, n. 2, p. 146-150, 2005.

LORENZI, H. Árvores brasileiras: manual de identificação e cultivo de plantas arbóreas nativas do Brasil. (ed.) Nova Odessa: Instituto Plantarum. v. 1, p. 368, 2002.

MARTINS, C. C.; NAKAGAWA, J.; BOVI, M. L. Efeito da posição da semente no substrato e no crescimento inicial das plântulas de palmito-vermelho (Euterpe espiritosantensis Fernandes - Palmae). Revista Brasileira de Sementes. v. 21, n. 1, p. 164-173, 1999.

MEROTTO, J, A.; SANGOI, L.; ENDER, M.; GUIDOLIN, A. F.; HAVEROTH, H. S. A desuniformidade de emergência reduz o rendimento de grãos de milho. Ciência Rural. v. 29, n. 4, p. 595-601, 1999.

NETTO, D. A. M.; Germinação de sementes de pau-de-balsa (Ochrama pyramidale Cav. Urb.) Bombacaceae. Revista Brasileira de Sementes. v. 16, n. 2, p. 159-162, 1998. 
SANTANA, D. G.; RANAL, M. A.; OLIVEIRA, M. C. Despolpamento e reguladores de crescimento na emergência de plântulas de espécies do gênero Pouteria. IX Simpósio Nacional Cerrado. ParlaMundi, 2008.

SILVA, D. B.; SILVA, J. A.; JUNQUEIRA, N. T. V.; ANDRADE, L. R. M. Frutas do cerrado. Embrapa Informação Tecnológica, p. 178, 2001.

SOUZA, E. R. B.; CARNEIRO, I. F.; NAVES, R. V.; BORGES, J. D.; LEANDRO, W. M.; CHAVES, L. J. Emergência e crescimento de cagaita (Eugenia dysenterica DC.) em função do tipo e do volume de substratos.

Pesquisa Agropecuária Tropical. v. 31, n. 2, p. 89-95, 2001.

SMIDERLE, O. S.; MINAMI, K. Emergência e vigor de plântulas de goiabeira em diferentes substratos. Revista

Científica Rural. v. 6, n. 1, p. 38-45, 2001. 